\title{
Travessias e interações sócio-verbais com práticas de escrita em weblog pessoais
}

\author{
Crossings and socio-verbal interactions with writing practices in personal weblog \\ Robério Pereira Barreto* \\ Universidade do Estado da Bahia, Santo Antônio de Jesus, Bahia, Brasil.
}

\begin{abstract}
Resumo: Este texto se inscreve como proposta que prioriza a interação sócio-verbal na escrita do weblog, por compreender que, nessa tecnologia intelectual há um modus de produção de linguagem multimodais e discursivas, por meio da qual, a conexão e a interação entre os escreventes/interagentes se completam e solidificam-se, através de práticas de escritas interativas. Relações sociais permitem as travessias discursivas, tendo como ponto de ancoragem os gêneros textuais realizados nos ambiente do weblog. Isto ocorre devido ao acordo estabelecido entre os participantes dessas comunidades que, falando o mesmo código e partilhando o capital social e linguístico nela existente se tornam viajantes no oceano de linguagens da web.
\end{abstract}

Palavras-chave: Weblog. Escrita do self. Interação sócio-verbal. Práticas de escrita. Linguagem Multimodal.

Abstratct: This text proposes to prioritize the socio-verbal interaction in the weblog writing process. It is understood that in this intellectual technology there is a modus operandi of multimodal and discursive language production, through which the connection and interaction between the writers / interagents complete each other and are solidified through interactive writing practices. Social relations allow discursive crossings and are anchored in the textual genres produced in weblog environment. This occurs due to the agreement reached between the participants of these communities who, by using the same code and sharing its existing social and linguistic capital, become travelers in the ocean of web languages.

Keywords: Weblog. Writing of the self. Social and verbal Interaction. Writing practices. Multimodal language.

\section{INTRODUÇÃO}

Este texto parte da perspectiva de que o processo de comunicação escrita ofertado pelas tecnologias digitais, sobretudo, aquele possibilitado pelas tecnologias intelectuais digitais, disponíveis na rede, exemplo o weblog, tem consequências sociais significativas nas práticas de escritas; de tal modo, que o self dos comunicadores desses espaços a todo o momento é colocado à sombra da realidade; isso dar a eles a oportunidade de conviverem diariamente com os vazios comunicativos da web. Isto leva à exposição de suas subjetividades, caracterizandoos como indivíduos humanos que, solto na sociedade dos bits se realizam como seres comunicantes.

Trata-se, na verdade, nesse ponto de vista de compreender o indivíduo que está nesse contexto e que vive em conexões com o mundo da tecnologia e da

\footnotetext{
* Professor Adjunto da Universidade do Estado da Babia - DCH - V - Colegiado de Letras Espanhol. Santo Antônio de Jesus - Bahia, Brasil, e-mail: jpgbarreto@gmail.com.
} 
linguagem, ambas resultantes de um processo de transformação sócio-técnico. Assim compreendê-la é importante para que

[...] o indivíduo humano e seu possível destino em meio ao torvelinho das transformações que estão atualmente ocorrendo. Trata-se de uma perspectiva extremamente importante, posto que afeta imediatamente - e não por meio das leis estatísticas dos movimentos sociais - o destino de cada um de nós. (SCHAFF, 1995, p. 99).

Nesse sentido, o homem contemporâneo está consciente ou não, de suas ações enquanto ser comunicante basilado em fundamentos de uma filosofia de ser homem ante a gama de signos que o leva à reminiscência de si ao produz linguagens no weblog como lócus de individuação pessoal. Dessa maneira no dizer de Maturana: "Todo ato na linguagem produz o mundo que se cria com outros no ato de convivência que dá origem ao humano: por isso, todo ato humano tem sentido ético" (MATURANA, 1995, p. 263).

No campo da linguagem, no qual, a tecnologia leva à provocação de um mundo de significados que promove o sujeito à compreensão de si e dos demais numa perspectiva de interatividade com o meio ético, social e político. Logo, não poderia ser diferente quando o sujeito da linguagem deixa vir à tona, por meio de discurso no weblog suas reminiscências culturais, sociais e linguísticas determinantes de sua identidade enquanto ser que se comunica pelos mais amplos sistemas tecnológicos de comunicação, desde sua concepção e permanência no ventre materno.

Para Habermas (1990), esse quadro promove a construção de um conjunto de elementos cuja semântica da comunicação é vista a partir de "sujeitos que interpretam a natureza e a si próprios em seu meio ambiente" (HABERMAS, 1982, p. 68).

Destarte, a produção de linguagem via weblog, sem dúvida, faz emergir as reminiscências do eu do comunicador, impulsionando-o à travessia sóciointeracional, posto que este parte do pressuposto de que

[...] linguagem fazemos nosso mundo de homens e nela nos fazemos, materializada, encarnada em corpos que se movem nos vastos campos do significante, do imaginário radical, do simbólico, percebemos distintas linguagens correlacionadas em suportes corpóreos específicos e cada qual lançando peculiaridades desafios à escola e, mais precisamente, às relações pedagógicas em sala de aula. E, à medida que mais complexos, isto é, plurais e diversificados, se fazem nosso mundos, mais amplamente urdidas são as linguagens que neles nos fazem e na educação se trabalham de forma proposital e sistemática, continuada. (MARQUES, 1995, p. 17).

No que se refere à produção e socialização dos selfs via sistema de linguagem postulado na rede mundial de computadores, faz-se importante compreender que eles são perpassados pelos códigos de linguagem que, ainda, por sua vez, são construídos nos parâmetros da escrita, mantendo assim forte relação com a oralidade, a qual é considerada como tecnologia intelectual secundária.

E penetra a escrita própria forma primeira da linguagem, fazendo-a oralidade secundária exigente de um vocabulário e uma sintaxe derivados da escrita [...] na 
verdade, essas tecnologias rearticulam imunidade processual rica de virtualidades as linguagens todas, transformam a oralidade e a escrita sem nunca dispensá-las em suas formas anteriores e colocam desafios outros à educação escolar. (MARQUES, 1995, p. 18).

$\mathrm{Na}$ realidade, a escola contemporânea precisa compreender os processos pelos quais os sujeitos estão construindo suas relações sociais na rede, visando com isso melhor entendimento de como o self de cada um é promovido à condição de sujeito da enunciação de linguagem. Por isso, um ponto de referência a essa observação é a maneira como os indivíduos usam as novas tecnologias intelectuais, isto é, há nesse contexto a produção de máscaras, estas possivelmente articuladas na linguagem simbólica da web.

A escola como lócus de ensino e aprendizagem de códigos, tecnologias comunicativas e saberes não pode ficar alheia a essa realidade e, portanto, deve inserir-se rapidamente no universo comunicativo proporcionado pelas novas tecnologias intelectuais usadas pela comunidade além do muro da escola; para com isso, poder interagir com a realidade do corpus socialmente edificado acerca da linguagem.

Consoante à tarefa da escola em formar sujeitos para a comunicação e articulação de saberes, nos quais se considera a interatividade como a base e o meio em que se efetivam os usos das tecnologias intelectuais na produção, armazenagem e rearticulação dos símbolos culturais; "as novas tecnologias da informação, mais do que recursos a que importa apelar, significam, para a educação escolar, especialmente para o trabalho em sala de aula, desafios outros que se imprimem às distintas articulações de linguagens, ao mundo, à sociedade, à cultura e às identidades sociais e singularizadas" (MARQUES, 1995, p. 19).

Esse processo deve ocorrer por meio do reconhecimento de que há uma tensão entre os sujeitos produtores e articuladores dessas linguagens - professores e estudantes/cibernautas - posto que estes últimos, fluentes e exímios articuladores de signos culturais contemporâneos, projetam e, até, absorvem selfs coletivo. À medida que transitam na rede digital articulam perfis e, exibindo, assim, seus corpos na linguagem da web, isto é, são criados perfis individuais e coletivos; nos quais a linguagem está apropriada à determinada inserção comunitária, a ponto de se forjar identidades, na perspectiva de ser aceito como alguém que deseja e partilha determinados pontos de vistas e interesses culturais e ideológicos.

Eis, pois, nesse contexto o princípio da travessia sócio-interacional do webenunciador e webleitor que através de postagem no weblog transita entre os universos da linguagem, revelando seus sentimentos e habilidades no ciberespaço.

No contexto da linguagem, a ação do self e do cotidiano do participante de weblog é articulada na ação da linguagem. Isto é, o self do cibernauta praticante e partícipe de weblog é todo instante fragmento e diluído na dinâmica da linguagem digital.

Reconhecer isso é um desafio para ele e para a família e para a escola, posto que, o entendimento que esse sujeito tem da cultura, da sociedade e de si próprio, ultrapassa a concepção tradicional que as instituições têm da linguagem e do eu individual e coletivo partilhado na web. 
Isto acontece porque as linguagens propostas pelas tecnologias intelectuais, nesse caso especificamente do weblog, desafiam o sujeito a ir além dos padrões comunicativos até então possibilitados pela escola e os meios tradicionais de produzir e socializar saberes.

Os educandos buscam a reconstrução de seus saberes apelando aos saberes do professor transformado em orientador de estudos ao mesmo passo que fiador da certificação social dos saberes reconstruídos nas efetivas aprendizagens escolares. [...] o que da educação se exige é que conduza ela à competência para a programação autônoma e a seleção criteriosa do que se vai buscar nos meios disponíveis e dos usos eu disso se vão fazer na concidadania das competências comunicativas ampliadas e de todos por igual, concidadania, por outra parte das relações interpessoais densas e calorosas. (MARQUES, 1995, p. 21).

A contemporaneidade, caracterizada pela presença das tecnologias intelectuais, comunicacionais e informativas tem possibilitado a interação entre linguagem, corpo e técnica que, de certo modo, garante a reminiscência do self na web. Tal questão acontece quando os participantes desse universo comunicativo, relacionando-se com a linguagem de modo singular praticam os princípios da razão prática com a qual realizam a interpretação dos signos de selfs individuais e coletivos na rede.

Para Habermas (1990) essa "unidade da razão teórica e da razão prática tornase o problema-chave das modernas interpretações do mundo" (HABERMAS, 1990, p. 21). Assim sendo, coloca-se a linguagem como referência da complexidade vivenciada no contemporâneo, sendo esta possibilitada pelas tecnologias intelectuais que trazem em sua essência o princípio da "virada linguística". Conforme Habermas (1990) é na linguagem a justificativa de que o homem se afirma e se reconhece no ato comunicativo: seja na web, ou, nos lugares sociais cotidianos - família, comunidade, escola, etc. - onde há, sem duvida, elevado grau de complexidade humana e, nela se edifica e se fragmenta o self a cada ato comunicativo.

Os sujeitos comunicantes, à sua maneira buscam fragmentos de si na própria linguagem para, com isso, realizarem as travessias sócio-interacionais, ampliando a suas possibilidades enunciativas nas ações comunicativas no weblog.

Na complexidade da vida humana em sociedade, justifica-se a afirmação de que a linguagem faz nosso mundo de homens e nele nos faz desde o momento em que a concebemos como movimento de atos pragmáticos doadores de sentido atos de imprimir significados e de sermos reconhecidos como sujeitos singularizados ao mesmo passo que imersos em nossa humanidade genérica, onde importa nos entendermos pela comunicação doadora de sentidos ao que temos em comum. (MARQUES, 1995, p. 26).

No campo da comunicação mediada pelas tecnologias intelectuais, o weblog é espaço-referência à construção e à manutenção de self por meio de conexões simbólicas mútuas. "interações recíprocas em que os organismos participantes realizam suas ontogenias individuais e denominamos comunicativas as condutas coordenadas mutuamente desencadeadas, entre os membros de uma unidade social.” (MARQUES, 1995, p. 32). 
A produzir um discurso e publicá-lo na web, o sujeito se expõe à comunidade na medida em que se 'revela' como sujeito da linguagem e, portanto, produzir sentidos a si e aqueles que interagem no mesmo espaço comunicativo. Atribui-se a estes indivíduos sentidos culturais por meio das interações pretendidas no vazio da linguagem.

[...] às interações determina o curso delas, surge a linguagem humano com sua característica-chave de permitir a quem nela opera descrever-se a si mesmo e às circunstâncias, de forma que o próprio domínio lingüístico passe a fazer parte das interações possíveis. O operar na linguagem permeia toda a ontogenia do homem num domínio de convivência cujas interações recorrentes individualizam os sujeitos na coordenação linguística. É a história das interações recorrentes que permite um acoplamento intersubjetivo efetivo, em que as palavras são ações, não coisas que passam de um lado ao outro. (MARQUES, 1995, p. 33).

Em verdade, todo ser humano se reconhece e conhece aos seus semelhantes no ato de linguagem. Por isso, é nesse universo de comunicação mediado pelo contínuo proposicional da linguagem que nos reconhecemos num contínuo existir nos mundos linguísticos e semânticos produzidos com os outros seres humanos.

Hoje, nos reconhecemos na diversidade sígnica possibilitada pelas novas tecnologias intelectuais ofertadas pela web que, de acordo com Castells (1997), garantem a ampliação das relações sociais conforme se quer ver a realidade em que a linguagem é proposta. "Não vemos a realidade como é, senão como são nossas linguagens. E nossas linguagens são nossos meios de comunicação. Nossos meios de comunicação são nossas metáforas. Nossas metáforas criam o conteúdo de nossa cultura" (CASTELLS, 1997, p. 360).

À medida que se pensa em dialogar via web, ver-se diante de si um processo complexo de linguagens no qual, a comunicação leva indubitavelmente à singularização do sujeito que se fragmenta na interação com os membros da comunidade. Dessa maneira, o sujeito é visto com um corpo que, determinado pela ordem social empreendida pelos interlocutores no ato de sua fala, conversação via weblog participa de travessias que, somente a linguagem é capaz de lhe proporcionar.

Numa perspectiva lacaneana de sujeito, poder-se-ia compreender que, na contemporaneidade a presença das tecnologias intelectuais atuando como suporte à construção do self permite a materialização da linguagem simbólica através da palavra. "O sujeito se constitui no ato mesmo de sua instalação numa estrutura simbólica de linguagem que o assujeita e o interpela, assumindo ele, em troca, uma identidade, um lugar simbólico próprio como doador de sentido" (CALLIGARIS, 1992. p.80).

Nesse processo, há que se destacar que, o self produzido na reminiscência e no espaço da web, sobretudo no weblog, parece haver um desejo notável de ser reconhecido e desejado pelo outro da linguagem, imbricando dessa maneira na satisfação de ser na e para a linguagem. Nesse sentido Marques (1995) diz que isso ocorre devido a este sujeito da linguagem possibilitar travessias em que o vazio "[...] funda-se o desejo de ser desejado pelo Outro; e na satisfação desse desejo funda-se a satisfação de todas as necessidades do sujeito. Dessa forma, subjetividade não se aninha na interioridade do organismo, mas está sempre em germe no desejo do 
Outro, que não precisa de um suporte material senão para ele mesmo materializarse” (MARQUES, 1995, p. 38)

A comunicação é imperativa à formação do self de qualquer indivíduo seja qual for seu contexto sociocultural, isto é, o sujeito da linguagem assume-se enquanto dono de si e, também, portador de significado à medida que amplia os limiares das subjetividades, revelando-se assim autêntico ser de linguagem. "Reconstrução dos conhecimentos compartilhados dilata os horizontes de vida do sujeito e o liberta, mas ao mesmo tempo, lhe traz novos desafios e ameaças por haver ingressado num mundo sacralizado, reservado a poucos, aos donos do poder [...]" (MARQUES, 1995, p. 38-9).

Afirmar-se, com isso, que o lugar dos significados da aprendizagem comunicativa ao longo da vida são as trocas e as travessias possibilitadas pela interação sócio-verbal que levam os sujeitos encontrarem na prática comunicativa no weblog ponto de referência. Entretanto, comunicar-se via web resulta dos usos efetivos de conexões simbólicas, em que o desejo de ser vai além da racionalidade prática verbal, a qual se constrói nas singularidades do dizer e fazer do sujeito com a linguagem para se identificar e ser aceito pelos membros do grupo social.

Para Marques (1995) a vida em sociedade, especialmente, a que se vive hoje, ocorre no tensionamento entre linguagens e desejos de ser socialmente visualizado pela comunicação. "Constrói-se a vida humana na tensão entre a produtividade do sujeito prático-empírico, sujeito da técne exigida pela sobrevivência social, e o sujeito da palavra significativa, sujeito da poiésis ligado à dimensão criativa dos muitos mundos possíveis e enraizado no imaginário social insubmisso às formas da domesticação e da vontade de poder” (MARQUES, 1995, p. 39).

A partir dessa compreensão, ver-se, portanto, que as tecnologias intelectuais e de comunicação assume lugar de destaque no fazer da linguagem, posto que se reconstrua no interdiscurso da palavra como ação humana de construção dos saberes no complexo relacional estabelecido pela prática cotidiana de se produzir e socializar linguagens.

Para Marques (1995) a tecnologia é perpassada pela sincronia da linguagem no fazer da razão prática. Por isso, "tecnologia é a forma corpórea em que se encarna a linguagem do fazer e do saber, ou melhor, a palavra da ação e a ação da palavra em simultaneidade" (MARQUES, 1995, p. 39).

As reminiscências do self presentes na linguagem do weblog podem ser compreendidas como as carências afetivas e individuais de cada participante, eles buscam serem vistos, reconhecidos e representados na organização social e discursiva, onde a linguagem os caracteriza com sujeitos carregados de significados no complexo de suas existências.

As carências de indivíduos socialmente organizados interelacionam-se e combinamse em sistemas de desejos barrados, isto é, condicionados por meios diversos de produção, participantes do estoque comum de um mesmo complexo cultural e inscritos em sistemas de normas e valores. [...] sendo o processo histórico-social mediado pela atividade prática dos sujeitos e pela organização de suas interações no âmbito de um quadro cultural (MARQUES, 1995, p. 40). 
Existem nesse contexto, atos de linguagens que são realizados por sujeitos em busca de si. Por isso produzem na linguagem o seu mundo ideal e tem como espaço de interatividade e meio para as travessias, o weblog. Aí, o sentido proposto é de mediar às relações, visando assim, conhecer a maneira em que se "formam os conjuntos semânticos da comunicação, a partir dos quais os sujeitos interpretam a natureza e a si próprios em seu ambiente” (HABERMAS, 1982, p. 68).

O ambiente de comunicação - weblog - proposto pela web a todos nós vai além dos aspectos social, político e econômico, até porque nele veiculam saberes e informações originárias do fazer humano através da linguagem, na qual está o espírito da ética que, de modo subversivo transcorrer os modelos até então vigentes.

$\mathrm{Na}$ web a produção e uso dos signos são convencionalizados pelo coletivo, permitindo a todos percorrem longas travessias nos campos das socializações e interação sócio-verbal, uma vez que a ordem nesse espaço é ruptura de conceitos e questões tradicionais da comunicação.

Essa transmutação da técnica, instância consciente em que o individuo age voluntariamente segundo regras aplicáveis à própria prática pessoal, torna-se assustadora ante a inevitável fuga para a frente das tecnologias que de continuo tornam não só as coisas, sobretudo os saberes sobre as coisas e o controle sobre elas. Em muito se reduzem as competências exigidas do usuário individual devendo submeter-se os interesses privados às políticas públicas. Resultam as tecnologias e os usos delas de um processo coletivo organizado, subversivo das anteriores relações sociais e institucionais (MARQUES, 1995, p. 41).

A esse procedimento acoplam-se os sentidos pretendidos pelo self do comunicante de tal modo que o caráter simbiótico da linguagem leva à humanização daqueles que se realizam na rede enquanto ser do discurso possibilitado pelo weblog. Assim sendo, a posição do sujeito efetivamente relacionado com os signos da web é de que, na medida em que se pronunciam deixa vir à baila seu self caracterizado pelos vazios da linguagem a qual se realiza.

\footnotetext{
Nesse caráter simbólico, fundante da linguagem, se correlacionam as distintas linguagens em suportes corpóreos específicos das determinadas formas que assumem. De início, o corpo da linguagem são os corpos dos interlocutores, nos quais se inscreve a fala/escuta com as exigências postas a toda a linguagem, de reciprocidade, simetria, compreensibilidade e aceitabilidade, e a essa forma primeira de articulação de linguagens acompanham as técnicas da expressão corporal e da comunicação das razões que se aduzem. [...] o surgimento de uma articulação de linguagens encarnada em novos suportes que são as máquinas com que os homens se comunicam, dotando-as da capacidade de processarem e intercambiarem informações (MARQUES, 195, p. 48)
}

Os espaços para construção de sentidos, abertos por meio das tecnologias intelectuais, sobretudo, weblog pessoais são fundantes à nova ordem de pensamento e à transformação do self em linguagem. Com isso se busca os preenchimentos dos 
vazios existenciais dos produtores de discurso nesses ambientes virtuais de comunicação e relações sociais nas quais se realizam os desejos de ser sujeito, imprimindo assim significados ao seu caráter; mesmo que este seja virtualmente pensando para a comunicação e interação na web.

Nesse sentido Marques (1995) chama a atenção para o desejo de ser na linguagem. Isto porque $\mathrm{o}$ ato de ser na escrita posta no weblog pessoal, indubitavelmente ocorre em virtude de o enunciador está a deriva de si, Neste mesmo raciocínio Capra (1996) pondera: "ser homem é existir na linguagem, o que inclui fundamentalmente o mundo interior de símbolos, de pensamentos abstratos, de conceitos, de autopercepção, de reflexibilidade, onde criamos a nós mesmos à medida que sabemos que sabemos e, com os outros, criamos nosso mundo de entendimentos compartilhados(CAPRA, 1996, p. 227).

Para Marques (1995) isso ocorre em virtude de haver na contemporaneidade o entrelaçamento de diversas linguagens que se corporificam nas interações sócioverbais possíveis via web, a qual propõe àqueles que se dispõe a dialogar com os seus pares, mesmo que essa igualdade seja forjada na iconicidade das tecnologias intelectuais disponíveis.

Nesse particular, expõe-se o papel do sujeito na articulação dos significados atribuídos à linguagem; é nela que se articulam através de fios semióticos que levam à distinção dos espaços comunicativos de redes sociais - Weblog, Whatsapp, Facebook, etc. - à forma de linguagem aplicada; vindo dessa forma, haver o reconhecimento das "diversas linguagens e suas recombinações, cada qual com dinâmica própria, com sua própria lógica clandestina de ritmos e estilos, de virtualidades operativas." [...] as potencialidades próprias da linguagem humana embutida numa teia de convenções sociais e culturais. (MARQUES, 1995, p. 51).

$\mathrm{Na}$ contemporaneidade fazer-se sujeito de linguagem e, portanto, reconhecese como tal em meio a miríade de signos, conforme Marques (1995) é perceber o surgimento e articulação das linguagens como elementos da expressividade do self, numa perspectiva individual e coletiva. Isso, sem dúvida, acontece porque "Ser humano é fazer-se dotado de consciência reflexiva por meio da linguagem e de todo o contexto social nela incluso." (MARQUES, 1995, p. 53).

Nesse decurso, ver-se o deslocamento das reminiscências do self como travessia, em que se religa o passado da escrita íntima no diário individual, guardado a "sete chaves" e enunciação no weblog como prática coletiva de exposição das angústias dos sujeitos ao se apresentam por meio dos vários signos instituídos pelo suporte da web; tendo no weblog suas diversidades e regras cuja produção linguísticocomunicativa é instituída na proposição de que " $\mathrm{Na}$ linguagem se articulam também culturas diversas. Não há como justificar uma origem comum para as línguas hoje faladas; cada língua denuncia a pertença a uma comunidade social específica." (MARQUES, 1995, p. 55).

Lévy (1996) compartilhando dessa ideia informa a respeito da virtualização da linguagem enquanto invenção humana para a comunicação e socialização de saberes em contexto potencialmente desenvolvido para essa finalidade. A linguagem na perspectiva levineana é reinventada para finalidades criadas pelo coletivo, cuja intencionalidade é marcada pelo desejo de se produzir saberes com 
os quais vislumbre-se a reminiscência e, em seguida a travessia do self na e para a comunidade, seja ela qual for.

Assim sendo, à medida que, o sujeito virtualiza seu self por meio da escrita no weblog pessoal, colocando-o à apreciação pública. Nela materializa seus desejos de ser a partir da abstração dos corpos intersubjetivo da linguagem. Este corpo vai ao encontro do corpo público da linguagem que o reconhece na interação sócio-verbal, em que a reminiscência de si. "Nesse corpo ampliado, modificado, virtualizado, a exterioridade técnica se faz pública ou partilhável, contribui para forjar uma subjetividade coletiva mais ampla, ao mesmo passo que exige ser internalizada de novo, só assim ganhando efetividade como linguagem e se fazendo eficaz" (LÈVY, 1996, p. 73).

Na web há o espraiamento dos limiares da comunicação e isso autoriza novas articulações com os sentidos existentes no corpo social da mensagem, indo, assim, ao encontro de novas articulações, sendo que nestas, escrita de si e da coletividade se imbricam a tal ponto; a inserção de elementos situacionais de comunicação explicitam as reminiscências do self de cada participante do processo comunicativo no weblog. "A nova articulação de linguagens em abertura mais ampla não dispensa, antes exige de maneira integrada a oralidade e a escrita, potenciadas em suas virtualidades." (MARQUES, 1995, p. 60).

$\mathrm{Na}$ medida em que a comunicação via web leva a construção e publicização de caracteres individuais reconhecidos nas comunidades virtuais, os participantes desse sistema de troca de informação têm ao longo de seus atos comunicativos promovidos seu selfà aclamação e ou à execração. Isso ocorre porque a maioria dos sujeitos pratica essa linguagem constrói seus sentidos basilados na sistematização e nos usos efetivos de determinados códigos, sobretudo, nos linguísticos, os quais os identificam com pertencentes ou não à nova categoria comunicativa - discurso interacional - post e comentário no weblog.

Verifica-se, portanto, que à medida que a comunicação suportada pela web amplia os horizontes de acesso às informações, categorias até então cristalizadas, passam a assim um novo posicionamento frente a essa nova realidade; dizendo de outro modo, a escrita e as outras formas de produção de discurso passam-se a ser redimensionadas às exigências da página hipertextual da web, na qual se acoplam signos variados, demandando do sujeito, novos e sistemáticos saberes, quando do ato de escrever, ver e interagir via linguagem escrita.

Essa questão, segundo argumenta Marques (1995) é resultante da junção das tecnologias intelectuais primárias - oralidade e escrita - ao universo da tecnologia digital a serviço da descentralização temporal e espacial da linguagem na web. Permitindo assim, a velocidade na troca de informações e, sobremodo, a operacionalização de signos verbais e imagéticos - gestos - até então próprios da comunicação face a face.

Diante dessas questões, infere-se que a comunicação via weblog pessoal potencializa a exposição de saberes, angústias e desejos que até então eram escritos e guardados em diários individuais nos quais se mantinham segredos e confissões do self como se fossem algo inatingível.

Quanto às consequências dessas exposições pessoais, compreende-se que elas são ainda não foram mensuradas e, portanto, demanda outro estudo. Entretanto, 
pode-se perceber no diz respeito à produção da linguagem, esta possibilitou aos weblogueiros a travessia sócio-verbal, posto que a escrita no weblog seja suportada por novos mecanismos de linguagem, dentre estes se destaca a possibilidade de haver sincronicidade e a troca entre enunciador e enunciatário ocorrem instantaneamente através de comentários feitos aos posts.

\section{WEBLOG: ESPAÇO DE ENSINO DE GÊNEROS DISCURSIVOS E DIGITAIS}

Esta sessão discutir teórico e metodologicamente uma proposta de ensino de gêneros, na qual se utilize o blog como espaço para o ensino de escrita nas salas de aula, especialmente, na de Língua Portuguesa de escolas públicas, onde existam Centros Digitais de Cidadania - CDC, visando à melhoria do aproveitamento das ferramentas da internet para o acesso e ensino de aspectos da cultura escrita digital.

Esta proposta está ancorada nos julgamentos do Círculo de Bakhtin sobre linguagem e enunciação, através da Teoria dos Gêneros do Discurso (Bakhtin/Volochinov, 1981), cultura escrita de Olson (1995), combinando-as com os ideais de ensino de gêneros, propostos pelos pesquisadores em Didática da Escola de Genebra (SCHNEUWLY; DOLZ, 2004) e gêneros textuais digitais de Marcuschi (2000) e colaboradores que atuam no Brasil.

Nesse contexto, a Lei de Diretrizes e Bases (Lei 9.394/96 - LDB) em conjunto com os PCNs de Língua Portuguesa recomendam que o ensino e a educação básica devam ser voltados para o exercício e a compreensão da cidadania de maneira plural, até porque, nos próprios PCN's se colocou a Língua Portuguesa no campo das Linguagens, Códigos e suas Tecnologias.

A partir dessa questão se reconhecem os acessos de estudantes à escola pública plural; estes jovens têm sido considerados nascidos na geração digital. Este fato per si demanda um novo olhar para a ação professoral com o uso de dispositivos móveis - celulares e tablets - como hospedeiros de blogs; espaço para realização de gêneros discursivos como prática de linguagem escrita, à qual estão vinculadas questões de ensino de linguagens e gêneros da escrita digital tanto dentro como fora das escolas.

Não obstante às ideologias que reverberam os programas de inclusão digital das escolas, o acesso às tecnologias vem ocorrendo também através de iniciativas privadas, isto é, as famílias têm adquirido dispositivos móveis: celular, tablets, etc com acesso à internet, visando, sobretudo, a participação dos adolescentes no cotidiano digital e, por seu turno, melhoria na qualidade dos estudos de seus filhos.

Entretanto, ainda é pequena a capacitação e até mesmo a adesão dos professores ao uso do computador, dos dispositivos móveis e da internet, especialmente, do blog como ferramentas de e para o ensino de gêneros discursivos na escola. O que de fato é uma pena, pois há esforços governamentais para que o computador com acesso à internet sirva para se realizar melhorias na qualidade do ensino e da educação desde as series iniciais da Educação Básica até o Ensino Superior. 
Por outro lado, percebe-se que, mesmo isoladamente, tentativas têm ocorrido e com certo sucesso, mais ainda são ínfimas quando se trata de imensas possibilidades que a internet e o computador têm no sentido de ampliar os conhecimentos de professores e alunos no campo das linguagens; uma vez que vivências no ciberespaço são obrigatoriamente realizadas através do uso da escrita como tecnologia intelectual e isto é uma prática continua, sobretudo, fora da escola. Entretanto, ela [escola] ainda não tem consciência disso, ou se tem prefere silenciar diante de tais questões.

No campo da prática de escrita através do uso das ferramentas da internet, o que mais tem sido usado é o blog pessoal no qual a maioria dos estudantes tem participação efetiva. No que diz respeito à questão do uso da ferramenta para o ensino e aperfeiçoamento no uso de gêneros textuais por parte de professores e estudantes, constata-se que: esta prática é tímida, embora professores afirmem ter participação efetiva no ciberespaço, sobremodo, nas redes sociais em que fazem interações ao nível pessoal com parentes e amigos, bem como participando de comunidades virtuais de seus interesses individuais.

Diante desse quadro, as circunstâncias sugerem que, haverá melhor aproveitamento desses recursos e tecnologias, quando os professores efetivamente se dispuserem a participar de programas de formação continuada que tenha como escopo a formação e o uso das tecnologias de informação e comunicação -TIC -, como ferramentas para o ensino e aprendizagem de linguagens e cultura escrita; em que os gêneros do discurso sejam objetos de reflexão-ação, ação-reflexão quando praticados na escola e no âmbito digital.

Pode-se dizer que ainda é recente a presença de tais tecnologias no âmbito do ensino e aprendizagem de gêneros do discurso, principalmente no que diz respeito às práticas de linguagem nas quais os gêneros discursivos passam a ser considerados basilares para a comunicação e a interação verbal em nossa sociedade de letramento, inclusive digital.

Conforme já mencionado antes, não restaria dúvida de que uma formação continuada de professores tendo como princípio orientador as tecnologias digitais e suas ferramentas poderiam levar à mudança desse quadro. Até porque uma formação nesse sentido levaria a transformações epistemológicas e didáticas, oportunizando assim, a combinação e troca de vários fatores e experiências entre estudantes e professores ao atuarem juntos no ciberespaço por meio da prática de discursos escrito e eletrônico.

Isto, sem dúvida provocaria o desenvolvimento de práticas escritoras nas quais se empregariam conhecimentos que se articulariam entre o conceito abstrato de gêneros e a realização prática de linguagem em que os gêneros discursivos no espaço digital, blog se tornam comuns na atividade de produção de linguagem em escrita na sala de aula e fora dela, internet.

O desenvolvimento de práticas leitoras e escritoras, de reflexão sobre a docência e de transformação de práticas docentes relativas à leitura e à escrita, todas mediadas pelo contexto WEB, com proposta concreta de inclusão dos professores participantes na nova sociedade da informação e nas práticas de letramento digital (ROJO, 2006, p. 109). 
Nesse contexto, Rojo (2006) corrobora ao avaliar que tais ações sistematicamente planejadas podem conduzir ao entendimento de que o computador e a internet com suas ferramentas podem ser considerados como instrumentos cognitivos que auxiliam na aprendizagem dos sujeitos, especialmente quando vinculados ao ensino e aprendizagem de linguagem através dos usos de gêneros discursivos empregados de forma variada nos blog

[...] usar as tecnologias para limitar e regular os processos de aprendizagem dos professores-alunos, por meio da utilização de estilos e dinâmicas pré-concebidas de interação, trata-se de oportunizar um processo de apropriação das mídias pelos participantes que dela passam a fazer uso par analisar o mundo, acessar informação, interpretar e organizar seu conhecimento pessoal e representar o que sabem para outros (ROJO, 1999, p. 110).

Compreender isso é dar oportunidade a todos - professor e estudante - a participarem do ciberespaço e nele produzirem suas comunicações e interações através de enunciados, explorando assim, os elementos dos gêneros discursivos como possibilidade de construção de conhecimento através de recursos linguísticos e semióticos presentes na internet, blog.

Assim sendo, uma proposta de ensino de gêneros discursivos que tenha weblog como ferramenta de democratização social e cultural de saberes e conhecimentos, precisa ter apoio na comunidade escolar pública, especialmente entre - professores e estudantes - uma ação reflexiva afim de que "cada um se torne capaz de produð̨ir (grifo meu) interpretar diferentes textos que circulam socialmente, de assumir palavra e, como cidadão, de produzir textos nas variadas situações, gêneros discursivos" (grifo meu) (PCNS, MEC, 2000, p. 23).

Portanto, um projeto educativo comprometido com a democratização social e cultural e que atribui à escola a função e a responsabilidade de garantir a todos os seus professores e alunos, acesso aos saberes linguísticos necessários para o exercício da cidadania, certamente, incentivará a participação de todos ao ciberespaço; através da efetivação de uma cultura escrita em que se faça uso de recursos linguísticos e semióticos à disposição da escrita no âmbito do blog.

Nesse sentido, a escrita compreende um importante instrumento para a democratização da sociedade, porque a escrita possibilita a ordenação das sociedades na qual a psique humana torna-se autônoma.

O comportamento linguístico pode produzir uma mudança qualitativa na capacidade de comunicação do ser humano, por seu potencial intrínseco de articular aspectos do mundo com os quais convive. [...] Através do comportamento linguístico, o ser humano pode lidar não só com o mundo imediatamente presente, interativo, mas com mundos distanciados dele no espaço e no tempo. Ademais, pode lidar com o mundo real, visível e dado, mas com mundos possíveis (imaginados) e situações nãofactuais (NARASIMHAN, 1995, p. 193). 
Diante dessas afirmações pontuais, defende-se que o uso didático e pedagógico do blog como potencializador da escrita de professores e alunos do ensino básico ao superior, asseguraria a transposição didática de gêneros textuais variados - recados, diários pessoais, comentários, etc. - do suporte do papel cuja intimidade era preservada; para uma exposição pública na internet por meio da participação de todos no ciberespaço, quando da publicação de seus escritos no blog.

A exposição escrita, a partir do weblog faz com que o gênero discursivo seja ele qual for se torne público, independentemente de este ser formal ou não, posto que o enunciador especialista ou não na arte da escrita dirige-se a uma audiência mista, de forma aberta e estruturada de acordo com os princípios dos discursos digitais.

Numa perspectiva de ensino de gênero discursivo, em que se tem o blog como espaço potencializador de ensino de escrita (conforme já defendido anteriormente) é, pois, sobretudo esse ponto de vista em que se apoiam e se definem objetivos e características dessa proposta.

Os objetivos que se apresentam nessa proposição estão diretamente vinculados ao pensamento de que a internet precisa ser explorada pelos profissionais da educação de maneira sistemática para, em seguida, estes professores orientarem seus alunos para aproveitarem o mais que puderem da cultura da escrita presente nesse meio.

Dessa forma, objetiva-se:

a) mostrar aos professores as potencialidades que internet e blog têm como espaço onde efetivamente se pode realizar e vivenciar a cultura da escrita;

b) experienciar a cultura escrita digital através produção de gêneros discursivo a partir da criação de weblog pessoais;

c) interagir com elementos linguísticos e semióticos possibilitados pela internet e que auxiliam na construção de gêneros discursivos;

d) discutir a natureza metalinguística existente em atividades de escrita, tendo os gêneros discursivos como prática de linguagem e;

e) reconhecer os gêneros discursivos como objetos que representam e tomam o mundo como seu objeto representável quando exposto através da escrita no ambiente virtual.

Diante disto, pode-se afiançar à maneira de Olson (1995) que com a prática da escrita por meio dos gêneros discursivos leva-se à compreensão de que é através de recursos linguísticos e semióticos que se apreendem enunciações escritas, sobretudo, aquelas realizadas na via weblog. Portanto, se dirigir a um público maior e até desconhecido e, assim sendo, o enunciado na web tende a se tornar mais cuidadoso ao elaborar sua produção. Desse modo, isto exige do enunciador o domínio do gênero a que se aplica sua prática de linguagem.

Para Olson (1995) esta questão coloca a prática de linguagem escrita no plano de dominância, isto é, a escrita desde seu surgimento na sociedade ocidental exerce influência sobre os efeitos de pensamento, posto que, é através de formulações e de compreensões que os textos são expostos ao público, de modo que seu significado e sentido serão a eles atribuídos a partir da escolha do gênero discursivo no qual será redigido. 


\title{
1) As características determinantes à consecução dessa proposta são:
}

a) compreensão de que os gêneros discursivos devem ser explorados como instrumentos orientadores para a execução de práticas de linguagem contemporâneas, suportadas pela internet, especialmente, no weblog,

b) reconhecimento de que os profissionais da linguagem, sobretudo, os professores de língua portuguesa estão imersos no universo e cultura de escrita, letramento digital;

c) integração entre suportes convencional e digital - papel e computador - nos quais a prática de linguagem permite a cultura escrita encerrar consciências individuais e coletivas e;

d) entendimento dos aspectos linguísticos e semióticos da escrita no ambiente digital.

\section{2) Dimensões teóricas interativas, sociais e linguísticas no weblog}

As dimensões teóricas e práticas do weblog como espaço de ensino e práticas de linguagem escrita, manipulação e articulação de unidades linguísticas que estão e são organizadas por meio de gêneros discursivos.

\begin{abstract}
A bagagem que os alunos terão acumulado ao longo desses momentos de reflexão específica poderá ser reinvestida, com proveito, nas tarefas de escrita e de revisão prevista nas sequências. Em contrapartida, as sequências permitirão contextualizar certos objetivos de aprendizagem e dar-lhes mais sentido. (DOLZ, SCHNEUWLY, 2010, p. 98).
\end{abstract}

O enquadramento comunicativo - a exposição escrita no weblog acontece a partir do processo dialógico no qual se reconhecem aqueles que produzem gêneros discursivos - professores e estudantes - e um público variado - estudantes, professores, etc. - que, conectados à comunidade virtual por interesses mútuos, também se reúnem por interesses específicos para lê-los, bem como apreender e depreender alguma coisa relacionada ao tema veiculado na comunidade virtual.

Para Dolz e Schneuwly (2004) isso fica visível quando na comunicação mediada pelos gêneros discursivos, o ato de enunciar sentidos acontece nesse tipo de prática de linguagem por meio do uso de marcas linguísticas, dêiticos como pronomes em primeira pessoa, EU/NÓS e VOCÊS. (Eu vou contar para vocês meu final de semana). "A exposição constitui, de fato, uma estrutura bastante convencionalizada de aprendizagem - tanto para o expositor como para o auditório -, na qual um aluno, de certa maneira, toma o lugar do professor e experimenta esse mecanismo particular e bem conhecido, expresso no dito é escrevendo que se aprende (grifo e paráfrase meus)" (DOLZ; SCHNEUWLY, 2004, p.186).

Assim sendo, a exposição escrita no weblog é também uma oportunidade em que a consciência do escrevente é encerrada e seu comportamento é transmitido por meio da escrita. 
Olson (1995) provoca a todos nós dizendo: “[...] a aquisição da cultura escrita foi o principal fator no desenvolvimento intelectual, linguístico e social daqueles que estão direto e indiretamente ligados à cultura de escrita por meio do aproveitamento das oportunidades que a internet nos oferece especialmente no weblog (grifo meu)" (OLSON, 1995, p. 268).

Ainda nesse contexto, Olson (1995) expõe que a escrita é uma forma de se pensar como os mecanismos da escrita oferecem ao entendimento da modernidade. Nesse ínterim, o enunciador via escrita no weblog se torna um articulador de conhecimentos entre sujeitos que interagem com ele no mundo virtual em que o escrito regulamenta consciência e "Os argumentos centrais em favor da escrita foram o ato de escrever ser responsável, num primeiro momento, pela evolução de novas formas de discurso, entre elas a prosa ficcional e a ensaística, as quais refletiam uma nova abordagem ou compreensão da linguagem e uma visão da mente, mais subjetiva e reflexiva" (OLSON, 1995, p. 267).

Ocorre que o ensino de gêneros discursivos usando a internet, explorando blog como possibilidade de organização de ideias e saberes via escrita, reforça o ideal de Olson de quem "escreve conta com um vocabulário um tanto mais elaborado e usa construções com orações mais complexas. [...] as propriedades da escrita estão mais nítidas nos documentos científicos que nas cartas entre amigos" (OLSON, 1995, p. 271).

No que diz respeito aos modos e às práticas de linguagem escrita no blog pôdese inferir que, nesse espaço há o emprego de mecanismos de escrita que garantem que " o registro via escrita no weblog permite voltar atrás, reler, revisar e, portanto, criar um documento público, esses resultados são um tanto específico e não estão ligados meramente à prática de leitura e da escrita, mas ao trabalho educacional como um todo, não se manifestando, inclusive, antes e depois do momento adequado da publicização na internet (grifos meus) (OLSON, 1995, p. 271).

Nesse contexto, a prática de linguagem escrita no blog é uma das formas em que os gêneros discursivos podem ser empregados de maneira espontânea e livre; o que melhor substancialmente o desejo dos indivíduos em participarem do mundo da escrita.

Nesse contexto estudantes e professores ao serem defrontados com uma situação real, na qual podem produzir suas comunicações aproximando pessoas por meio de uma escrita suportada pela sincronicidade possibilitada pela internet, assume para si seu papel de sujeitos da linguagem e tecnologicamente articulados.

Assim sendo, se comunicar escrevendo no weblog torna-se uma maneira de se entender que, "a escrita leva à evolução de novas formas de discurso, novos gêneros, como cartas comerciais, resenhas, artigos de enciclopédia, listas, tabelas e outras formas de capitalizar os seus recursos" (OLSON, 1995, p. 272).

Desse ponto de vista, pode-se dizer que a prática de linguagem tanto de estudantes como de professores no ambiente virtual, weblog tem e leva a uma competência cognitiva e comunicativa nas formas de produzir um discurso até então pouco utilizada, no qual vários elementos dos gêneros discursivos são realizados, mesmo que não estejam na ordem cognitiva de ambos.

Já Bakhtin (1981) concebe a comunicação como um processo interativo, muito mais amplo do que a mera transmissão de informações, posto que haja 
multiplicidades de signos verbais, visuais e sonoros que atendem a este fim. Para ele a linguagem é interação social. O sujeito, ao falar ou escrever, deixa em seu texto marcas profundas de sua sociedade, seu núcleo familiar, suas experiências, além de pressuposições sobre o que o interlocutor gostaria ou não de ouvir ou ler, tendo em vista também seu contexto social. Isso, sem dúvida, a internet e weblog possibilitam de maneira simples e facilmente absorvida pela comunidade virtual.

No movimento de interação social, os sujeitos constroem os seus discursos por meio das palavras alheias, de outros sujeitos (e não da língua, isto é, já ideologizadas), as quais ganham significação no seu discurso interior e, ao mesmo tempo, geram as réplicas ao dizer do outro, que por sua vez vão mobilizar o discurso desse outro, e assim por diante. "A palavra dirige-se a um interlocutor: ela é função da pessoa desse interlocutor: variará se se tratar de uma pessoa do mesmo grupo social ou não, se esta for inferior ou superior na hierarquia social, se estiver ligada ao locutor por laços sociais mais ou menos estreitos (pai, mãe, marido, etc.)" (BAKHTIN, 1981, p.112)

A noção de interação verbal via gênero do discurso eletrônico é gerada pelo efeito de sentidos originado pela sequência verbal, pela situação, pelo contexto histórico-social, pelas condições de produção e também pelos papéis sociais desempenhados pelos interlocutores. Além dos aspectos linguísticos as condições de produção do discurso são definitivas para compô-lo no ambiente virtual, weblog.

O discurso linguístico atravessa as práticas sociais, assim como os gêneros discursivos virtuais não poderiam ser concebidos sem que se pensasse em sua relação com o social. Ali estão inseridos novos jeitos de pensar, agir e comunicarse em que "se acumulam formas de visão e compreensão de determinados aspectos do mundo" (BAKHTIN, 1981, p. 150).

O fato de moldar e aprender os modos sociais de ação prática de linguagem é também, apreender os modos sociais de se comunicar, de dizer. Existem indivíduos que, mesmo dominando a língua, se constrangem quando têm que participar de alguma atividade que exija habilidades de oratória como, por exemplo, participar de uma assembleia, de uma conversa entre pessoas de outras esferas da comunicação verbal, pelo simples fato de não possuir segurança na prática das formas de gênero daquela esfera face a face, entretanto, se sente a vontade para enunciar seus pensamentos no ambiente virtual através de convenções ao discurso eletrônico em que signos verbais são corroborados pelo distanciamento entre enunciador e enunciatário.

Por isso, todo signo resulta de um consenso entre indivíduos socialmente organizados no decorrer de um processo de interação. Nas palavras do teórico russo, "as formas do signo são condicionadas tanto pela organização social de tais indivíduos como pelas condições em que a interação acontece" (BAKHTIN, 1981, p. 44). Assim, tudo o que é ideológico é um signo, e sem estes não existiria ideologia, tampouco comunicação.

O signo, por sua vez, possui duas realidades, aquela que existe por si mesmo, e outra simbólica, aquela que reflete e refrata uma determinada realidade e que nem sempre é fiel a ela, por vezes pode distorcê-la ou aprendê-la de um ponto de vista específico (BAKHTIN, 1981, p. 57). 
Os domínios dos signos correspondem aos domínios do ideológico e, portanto, onde se encontra o signo, encontra-se o ideológico. Nessa perspectiva toda ação discursiva da internet é ideológica, uma vez que todo procedimento de comunicação e linguagem realizado na internet acontece por meio de signos convencionalmente aceitos pelos participantes das comunidades virtuais.

\begin{abstract}
Os signos - no caso aqui abordado, palavra, fala, língua, texto - só pode surgir em um terreno interindividual, ou seja, é necessária a existência de sujeitos que estejam socialmente organizados, constituindo, portanto, um grupo. Os signos são o alimento da consciência individual, ele a entende - a consciência - como um fato sócioideológico. A lógica da consciência é a lógica da comunicação ideológica. (BAKHTIN, 1981, p. 57).
\end{abstract}

Para Bakhtin (1981), o signo e a ideologia são englobados por um conceito fundamental: o discurso. Todo signo cultural quando compreendido e dotado de um sentido, não permanece isolado, ele vira parte da unidade da consciência verbalmente constituída por determinado segmento social, as comunidades discursivas que, nesse caso, blogs pessoais se encaixam perfeitamente nesse perfil de ambiente discursivo e comunicacional. Por isso, a importância de se ter a "língua, como realidade material específica da criação ideológica” (BAKHTIN, 1981, p. 25). Assim, a sobrevivência e a comunicação que o homem procura está na perspectiva de que o relacionamento social com seus pares surge com e nas práticas de linguagem, nas quais o material, o social e, consequentemente, o interacional pertencente ao mundo exterior dos sujeitos discursantes. "Para começar, as bases de uma teoria marxista da criação ideológica - as dos estudos sobre o conhecimento cientifico, a literatura, a religião, a moral, etc. - estão estritamente ligadas aos problemas de filosofia da linguagem. Tudo que é ideológico possui um significado e remete a algo situado fora de si mesmo" (BAKHTIN, 1981, p. 31).

A consciência individual só existe quando está carregada de conteúdo ideológico, esta só existe em um processo de interação social. A consciência individual está repleta de símbolos. Estes só aparecem nas relações entre indivíduos, porém não só dessa relação básica, mas depende também de uma organização social, de um grupo, para daí então um sistema de signos pode ser formado.

Tal ocorrência é realizada na produção dos textos em variados gêneros discursivos, quando cibernautas interatuam nas comunidades com seus pares comunicacionais no weblog, através do uso livre dos signos que, se transformando em palavra faz a representação mais clara e básica da comunicação social na web.

Assim, a palavra pode-se dizer, é neutra, pois ela pode ser utilizada com qualquer função ideológica. Ela é formada sem a utilização de qualquer instrumento extra-corporal, então se pode dizer que ela é o "material semiótico da vida interior, da consciência" (BAKHTIN, 1981, p. 37).

Nenhum signo cultural, quando compreendido e dotado de um sentido, permanece isolado: torna-se parte da unidade da consciência verbalmente constituída. Toda refração ideológica do ser em processo de formação, seja qual for à natureza de seu material significante, é acompanhada de uma refração verbal, como fenômeno 
obrigatoriamente concomitante. A palavra está presente em todos os atos de compreensão e em todos os atos de interpretação (BAKHTIN, 1981, p. 38).

Cada época e cada grupo social têm seu repertório de formas de discurso na comunicação sócio-ideológica, e cada forma de discurso social corresponde a um grupo de temas. Portanto, todo discurso, como signo ideológico, está marcado pelo horizonte social de uma época ou grupo social determinado. "A palavra se apresenta como uma arena onde se cruzam e lutam os valores sociais de orientação contraditória. Ela "(...) está sempre carregada de um conteúdo ou de um sentido ideológico ou vivencial" É o produto da interação viva das forças sociais, pois, a ligação entre as significações de um texto e as condições sócio-históricas deste texto não são secundárias e sim, indissolúveis” (BAKHTIN, 1981, p. 99).

Pode-se ver em Bakhtin (1981) que a palavra simbolicamente é um produto coletivo, ou seja, um fenômeno social, e é sempre apresentada dentro de um contexto ideológico.

Se a palavra é carregada de um conteúdo ideológico e seu sentido é determinado pelo seu contexto, a palavra ao ser usada em gêneros discursos, ela [palavra] deixa espraiar todo sua significação no ato enunciativo. " A enunciação enquanto tal é um puro produto da interação social, quer se trate de um ato de fala determinado pela situação imediata ou pelo contexto mais amplo que constitui o conjunto das condições de vida de uma determinada comunidade linguística" (BAKHTIN, 1981, p. 126)

É condição primordial compreender na concepção bakhtineana de interação verbal que, a enunciação, enquanto discurso, é interação, constituindo-se modo de produção social, não neutro, nem natural, funciona como suporte das representações ideológicas; é um confronto ideológico constituído através de processos histórico-sociais, e por isso deve ser encarada como formação ideológica que se manifesta pela competência sócio-ideológica de enunciador e enunciatário ao se encontrarem no ato enunciativo realizado no weblog.

\section{INTERAÇÃO SÓCIO-VERBAL NA PRATICA DISCURSIVA NO WEBLOG}

Ao desenvolver, através de pressupostos marxistas, uma filosofia da linguagem, Bakhtin (1981), encara a linguagem, como uma entidade viva e não inerte, considerando-a como um signo ideológico-social, que faz parte da interação entre os seres sociais, responsável pela reflexão e refração de suas determinadas realidades.

A linguagem é adaptável às mudanças comportamentais, pois há um movimento intenso da língua e das situações enunciativas com que a consciência do sujeito vai se constituindo, o que leva a crer no seu inacabamento. Com o advento da Internet muitos gêneros emergiram e materializaram-se no meio virtual, trazendo novas formas de comunicação gerada pela criatividade do internauta.

Para Bakhtin (1981), a interação verbal é um lugar de produção de linguagem e a forma dessa produção é o dialogismo. O autor russo já previa de certa forma 
que os enunciados produzidos no ambiente virtual apresentam um novo gênero discursivo, pois possuem conteúdo, estilo verbal e construção composicional que "fundem-se indissoluvelmente no todo do enunciado, e todos eles são marcados pela especificidade de uma esfera da comunicação. Qualquer enunciado considerado isoladamente é, claro, individual, mas cada esfera de utilização da língua elabora seus tipos relativamente estáveis de enunciados, sendo isso que denominamos gêneros do discurso" (BAKHTIN, 1981, p.79).

A utilização da língua como um processo com heterogêneas, múltiplas, variadas maneiras de composição é de grande importância para compreender que os diversos campos da atividade humana estão ligados ao uso da linguagem e a partir da intencionalidade, do interesse e da finalidade inerentes de cada atividade os enunciados linguísticos se realizarão de formas diversas.

Por entender a linguagem nessa dimensão, Bakhtin argumenta que a língua é inseparável do fluxo da comunicação verbal e, portanto, não é transmitida como um produto acabado, mas como algo que se constitui continuamente na corrente da comunicação verbal. Dessa forma, a realidade fundamental da língua para ele é a interação verbal.

Neste sentido, apoia-se na categoria teórica da interação verbal proposta por Bakhtin (1981) para conceber também o weblog enquanto espaço de produção de linguagem, portanto, oportunizador de interações via gêneros textuais. A interação entre os interlocutores é o princípio fundador da linguagem e se realiza sempre sob a forma de diálogo entre ouvinte e falante, mediado pela palavra, "modo mais puro e sensível de relação social" (BAKHTIN, 1981, p.36).

Dessa forma, se vislumbram as enunciações presentes no weblog como elementos da escrita nos quais o sujeito enunciador/escritor pressupõe um ouvinte/leitor e vice-versa, pois, toda comunicação discursiva é marcada pela compreensão e responsividade de outra pessoa.

\section{WEBCONSIDERAÇÕES}

Poder-se-ia encerrar temporariamente essa conversa dizendo: a produção de gêneros discursivos tendo o weblog com espaço para tal realização e consequente socialização para além de simples modismos; é uma necessidade contemporânea, visto que a comunicação via comunidades virtuais da internet é uma realidade no cotidiano de todos.

Assim sendo, apreender a técnica comunicacional e discursiva efetiva da interação, tendo no weblog a ferramenta facilitadora de produção de enunciados em que são realizados os mais variados gêneros discursos é fundamental para que a escola consiga se inserir no universo discursivo proposta pela internet, no qual a maior parte dos estudantes está inserida e realiza seus discursos. Entretanto ainda não associam sua prática de escrita ao conceito de gêneros discursivos que a escola sofregamente insiste em ensinar, pois não reconhece que, independentemente de qual seja o suporte, os estudantes são sujeitos de linguagem. E mais; são sujeitos da e na linguagem virtual. 
Por um lado, defende-se tese de que a escola, sobretudo, os profissionais da linguagem devem vir os espacos virtuais da internet, redes sociais - Facebook, whatssapt, weblog, etc. - como os meios que podem auxiliar no despertar de estudantes e até dos próprios professores para o uso efetivo e consciente das práticas discursivas na web. Quando isso correr os fundamentos da comunicação e da interação verbal da cultura escrita difundida pelas técnicas da escrita e do discurso virtuais formarão os pilares da travessia: do analógico ao digital.

Por outro lado, reconhece-se a efetivação dessa perspectiva no âmbito das escolas públicas, demandada à realização de programas de formação continuada de professores para atuar com as linguagens do ambiente digital.

Ademais se tenha como escopo de formação, práticas de linguagem e escrita que reconheça a internet e suas redes sociais como potencializadora de gêneros discursivos, e que através da construção de weblog pessoais e institucionais a cultura escrita da comunidade escolar será infinitamente ampliada, uma vez que se reconhecerá nos estudantes produtores e socializadores de discursos.

\section{REFERÊNCIAS}

BAKHTIN, Mikhail. Marxismo e filosofia da linguagem: problemas fundamentais do método sociológico na ciência da linguagem. São Paulo: Hucitec, 1981. . Estética da Criaşão Verbal. São Paulo: Ed. Martins Fontes, 2003.

Questões de literatura e de estética: a teoria do romance. São Paulo: UNESP, 1998.

BARRETO, Robério Pereira. Tecnologias intelectuais chat e weblog: modus de produção de linguagem na web (dissertação de mestrado). Salvador - Departamento de Educação - Programa de Pós-graduação em Educação e Contemporaneidade Universidade do Estado da Bahia - Uneb - Campus I - Salvador-BA.

CALLIGARIS, Contardo. Hello Brasil! Notas de um psicanalista europeu viajando ao Brasil. São Paulo: Escuta, 1992.

CAPRA, Fritjof. A teia da vida: uma nova compreensão científica dos sistemas vivos. São Paulo: cultrix, 1996.

CASTELLS, Manuel. A sociedade em rede: a era da informação: econômica, sociedade e cultura. São Paulo: Paz \& Terra, 1990.

DOLZ, Joaquim; SCHNEUWLY, Bernard. Relato da elaboração de uma sequência: o debate público. In. ROJO, Roxane et al. (org.) Gêneros orais e escritos na escola. Campina -SP, Mercado de Letras, 2004, p. 213 - 239. 
HABERMAS, Jürgen. Teoria de la acción comunicativa: complementos y estúdios previos. Brasiliense, 1990.

LÉVY, Pierre. O que é o virtual? Rio de Janeiro: Editora 34, 1996.

MARQUES, Mario Osório. A escola no computador:linguagens rearticuladas, educação Outra. Ijuí: Ed. UNIJUÍ, 2003.

NARASIMHAN, R. Cultura escrita: caracterização e implicações. In: OLSON, David; OLSON, David. A escrita como atividade metalinguística. In: OLSON, David; OLSON, David; TORRANCE, Nancy. Cultura escrita e oralidade. São Paulo; Ática, 1995.

ONG, Walter. Oralidade e cultura escrita. São Paulo; Papirus, 1994.

ROJO, Roxane et al. (org.) Gêneros orais e escritos na escola. Campina -SP, Mercado de Letras, 2004.

SCHAFF. Adam. A sociedade informática. 4. ed. São Paulo: Brasiliense 1995.

XAVIER, Antônio Carlos. Hipertexto e gêneros digitais: novas formas de construção do sentido. Rio de Janeiro: Lucerna, 2004.

O bipertexto na sociedade da informação: a constituição do modo de enunciação digital. Tese (Doutorado em Linguística). Campinas: Instituto de Estudos da Linguagem (IEL). Universidade Estadual de Campinas (UNICAMP), 2006. 